O estágio supervisionado apresenta-se como etapa fundamental no processo de formação profissional, especialmente de professores. Caracteriza-se como um momento em que o estudante tem a chance de vivenciar, mesmo que parcialmente, a prática docente. Nesse período o estagiário tem a oportunidade de recontextualizar as lições e conteúdos vistos em sala de aula para a prática, analisando as possibilidades e enfrentando os desafios. Para Barros, Silva e Vásquez (2011, p. 510), é no estágio que "o universitário tem a oportunidade de superar suas deficiências através da reflexão de sua própria prática, promovendo a contextualização dos temas trabalhados e a formação do pensamento crítico e reflexivo a respeito das questões científicas e sociais".

$\mathrm{Na}$ formação docente o estágio caracteriza-se como o período em que o aluno passa a conectar o campo teórico à prática; trata-se de o professor em formação conhecer e experimentar sua área de atuação de perto, bem como seus prós e contras. $A$ partir do contato com o "chão da escola" o acadêmico poderá tomar a decisão se irá dar continuidade, ou não, ao exercício de sua formação e, consequentemente, ingressar de forma efetiva no professorado. O estágio é visto, por muitos, como um divisor de águas em um curso de Licenciatura, afinal, é quando os conhecimentos, os métodos, as técnicas e a didática aprendidos em sala de aula serão postos em teste, assim como o próprio estudante/estagiário. Desse modo, são de fundamental importância as orientações que os estagiários recebem no ambiente acadêmico, pois nem sempre a impressão que o estagiário tem do meio escolar é determinante para definir sua afinidade ou não com a docência, pelo contrário, é preciso que ocorram outras visitas à escola e que ele possa ir se conscientizando, gradativamente, sobre a realidade de sua profissão.

Com seu caráter indispensável para a formação, o estágio é um momento de ampliação do universo cultural dos estagiários, seja no âmbito das relações com os colegas de trabalho, mas principalmente com os alunos (crianças, jovens e adultos com experiências únicas). Nesse contexto, o estagiário tem o papel de promover um ensino que vise a um desenvolvimento do seu aluno para um desempenho na sociedade na condição de cidadão, indo além de uma mera absorção passiva e reprodutiva de ideias, conceitos e teorias; trata-se de ensinar a exercer a cidadania com consciência (SCALABRIN; MOLINARI, 2013).

A fim de compreender melhor a relevância do estágio na formação profissional de professores, o texto que se apresenta traz uma revisão bibliográfica e relatos da experiência de alguns autores com a referida temática. Diante disso, busca-se inicialmente fazer referência a um entendimento do que é o estágio e sua importância para a formação de professores; em seguida discutir as alterações que essa fase provoca nos discentes dos cursos de Licenciatura e, por fim, analisar a construção da identidade docente na atualidade.

\section{ESTÁGIO: TEORIA E PRÁTICA}

A Licenciatura é a modalidade de curso superior voltada à formação de professores, tendo em vista o ingresso de jovens e adultos na carreira docente. Ao entrar num curso de Licenciatura, independentemente da área, o estudante passa a conhecer teo-

\footnotetext{
A expressão "chão da escola" é aqui empregado com inspiração do professor e pesquisador Carlos Rodrigues Brandão, em sua obra "Nós, os humanos: do mundo à vida, da vida à cultura" (2015).
} 
rias e conteúdos e realiza estudos práticos acerca da sua futura área de atuação profissional. No decorrer dos semestres chegam as disciplinas voltadas às áreas específicas, direcionadas à prática docente, como a Didática e as Metodologias de Ensino. É essa a ocasião em que o estudante se vê inserido em um curso de Licenciatura, isto é, quando chega o momento do estágio, o que em alguns casos provoca estranhamento, embora o acadêmico tenha consciência de estar cursando uma Licenciatura.

Conforme Scalabrin e Molinari (2013), o estágio é um momento singular e determinante; é a partir dele que os acadêmicos concluem, com base em suas percepções do ambiente escolar, se querem ou não seguir a carreira docente, gerando níveis consideráveis de evasão dos cursos de Licenciatura nesse período. Afinal, nem todos se sentem confortáveis e preparados para o exercício da docência. A complexidade e os estereótipos dessa profissão podem gerar receios aos futuros professores. Nesse sentido, essa fase de vivências e mutualidades, de trocas entre os estagiários, acaba agindo como uma espécie de seleção entre os discentes das Licenciaturas, fazendo com que aqueles que possuem o desejo de atuarem e enfrentarem os desafios permaneçam nos cursos, acarretando avanços e recuos na formação (SCALABRIN; MOLINARI, 2013). Nesse contexto, o estágio supervisionado é

[...] indispensável na formação de docentes nos cursos de Licenciatura, é um processo de aprendizagem necessário a um profissional que deseja realmente estar preparado para enfrentar os desafios de uma carreira e deve acontecer durante todo o curso de formação acadêmica, no qual os estudantes são incentivados a conhecerem espaços educativos entrando em contato com a realidade sociocultural da população e da instituição. Como preparação à realização da prática em sala de aula, o tradicional estágio se configura como uma possibilidade de fazer uma relação entre teoria e prática, conhecer a realidade da profissão que optou para desempenhar, pois, quando o acadêmico tem contato com as atividades que o estágio Ihe oportuniza, inicia a compreensão daquilo que tem estudado e começa a fazer a relação com o cotidiano do seu trabalho (SCALABRIN; MOLINARI, 2013, s/p).

Assim, além de um momento que busca refletir sobre o desenvolvimento de competências específicas da profissão e o aprendizado por parte do estagiário, o estágio situa-se como uma atividade supervisionada. Busca, portanto, dar subsídios aos estagiários, por intermédio de um professor orientador e recursos desenvolvidos (tais como os planos de aula e miniaulas orientadas e acrescidas de sugestões do professor orientador da universidade), para que assim os pratiquem futuramente em seu exercício de docência. O que se deseja é que o período de estágio seja para os acadêmicos (futuros professores) um momento de experiência única e enriquecedora, que contribua para o desempenho de um trabalho consciente, a fim de evitar situações extremas (por exemplo, excesso de autoritarismo ou ausência de preparo do conteúdo em sala de aula) na realização de quaisquer atividades com os seus futuros alunos.

Por ser considerado, nas palavras de Pimenta (1994, p. 121), uma "atividade teórica instrumentalizadora da práxis do futuro professor", o estágio é uma oportunidade para o estudante se aproximar da profissão e "vivenciá-la". Assim, o estágio também é um momento em que os estagiários necessitam refletir sobre as "práticas docentes" inspiradoras no sentido positivo e aquelas negativas. É preciso ver o que se pode ter como influência para uma futura atuação docente e o que não deve ser reproduzido/ 
mantido na forma de atuar na docência. Tal preocupação se valida, essencialmente, em virtude de muitos professores ainda restringirem suas aulas ao formato tradicional, ${ }^{5} \mathrm{o}$ que em muitos casos pode refletir-se nos estagiários de forma direta, fazendo com que estes perpetuem esse método de ensino ao se tornarem professores efetivos.

A prática docente restrita à imitação de modelos, ou mesmo chamada de "artesanal" por alguns autores, ainda é uma atividade recorrente nas escolas, como afirmam Pimenta e Lima (2005/2006). O pressuposto dessa concepção é o de pontuar o ensino como algo constante, invariável, bem como os estudantes, ou seja, é concluir de forma equivocada que o ensino e os alunos não se alteram ao longo dos anos, descaracterizando as transformações do espaço e da sociedade. De tal modo, não há ou não se leva em consideração as transformações históricas e sociais, as quais são frutos de um processo de democratização do ensino, que propicia maior inserção social dos sujeitos, passando a ter direitos ao uso dos espaços e serviços, por conseguinte, ao ensino e aprendizagem (PIMENTA; LIMA, 2005/2006).

À medida que se realiza a inserção social dos alunos no processo de escolarização, as crianças e jovens passam a ter acesso e direito à educação, independentemente de sua realidade social. Na medida em que práticas e instrumentos são postos tradicionalmente como exemplos eficientes a serem seguidos, a escola limita-se à função de ensinar, desconsiderando o aprendizado dos alunos, afinal, se aprendem ou não o problema é deles, de sua cultura, a qual, tradicionalmente, é diversa daquela valorizada pela escola (PIMENTA; LIMA, 2005/2006).

Conforme Cury (2003, p. 55), "educar é acreditar na vida, mesmo que derramemos lágrimas. Educar é ter esperança no futuro, mesmo que os jovens nos decepcionem no presente. Educar é semear com sabedoria e colher com paciência. Educar é ser um garimpeiro que procura os tesouros do coração". Assim, é no estágio que o acadêmico de Licenciatura deve refletir sobre o "ser" e "fazer" da profissão docente, não só no sentido de perceber o que pode ou não ser melhor para os alunos, mas trata-se de se colocar no lugar deles. $O$ estagiário deve assimilar que em primeiro lugar ele também é aluno, obviamente que já em um nível superior de formação, entretanto ele sabe bem como pensava (quando integrante da Educação Básica) e como pensa (Ensino Superior), podendo discernir o que é proveitoso ou não às aulas. $O$ estágio deve contribuir para que os futuros professores percebam os dois lados da situação supracitada e saibam ponderar entre o que é praticado e produz bons frutos e aquilo que não gera benefícios ao ensino. Nesse contexto, Pontuschka (2012, p. 000096-000097) adverte que

[...] o estágio não é tão somente uma questão de cumprimento da legislação do MEC, mas uma forma de conhecer minimamente a realidade escolar através das oportunidades de entrar na escola não mais como aluno do ensino básico, mas como candidato a futuro professor com a oportunidade de exercer a docência e

\footnotetext{
Sistema de ensino pautado na elevação da figura do professor como o detentor do saber e os alunos como os receptores deste, além de atividades fundamentadas na memorização maçante de dados, os quais não colaboram para um desenvolvimento intelectual do aluno, mas apenas com um cansaço psicológico. Não há uma variação nas metodologias utilizadas, restringindo-se basicamente ao uso de quadro/lousa, giz/pincel e livro didático; além de ser um modelo de ensino visto como ultrapassado e exaustivo, não só para os alunos, mas também para os professores (CAVALCANTI, 2010).
} 
enfrentar classes de alunos reais e não imaginários. É a possibilidade que se abre para dar início à profissionalidade, com o compromisso de os alunos compreenderem a mensagem, fazendo-os refletir sobre temas e propostas específicas.

Um ponto que origina discussões durante os estágios supervisionados nos cursos de Licenciatura é a questão da união entre teoria e prática, principalmente por tratar-se de dois elementos que devem ser essencialmente ligados no intuito de promover um bom aproveitamento ao ensino. Há um dizer de que os cursos de Licenciatura formam professores, mas não os prepara para o "chão da escola", o que fundamenta o discurso dos recém-formados de que a Graduação não dá base para a atuação em sala de aula. O que boa parte dos licenciados pontua, entretanto, não significa necessariamente que a Graduação não proporciona formação para a atuação em sala de aula, mas sim que é necessário que sejam feitas maiores aproximações dos conteúdos que são ministrados na Academia com aqueles das escolas, a fim de elucidar esses conteúdos que serão ensinados ainda no período de formação docente.

Vale ressaltar que, mesmo nos dias de hoje, existem algumas tendências nos cursos de formação de professores que acabam realizando uma capacitação voltada, em sua maioria, ao Bacharelado, direcionando os discentes a pesquisas desvinculadas do campo da educação, ou então, restringem a formação às teorias. Dessa forma, isso pode acarretar a formação de professores com pouco contato com as escolas até o estágio, fazendo desse um momento ímpar para agir na aproximação e vinculação do acadêmico ao meio escolar, o que por vezes não aproxima como deveria.

Conforme Rodrigues (2013), entretanto, a Licenciatura acaba se sobressaindo em relação ao próprio Bacharelado, a ponto de que gera profissionais que poderão atuar ora na pesquisa, ora na docência, ou mesmo nas duas de modo concomitante, formando um profissional prático/atuante e ao mesmo tempo reflexivo, que possui uma formação específica para o professorado.

O tempo mínimo de duração dos cursos de formação de professores em nível superior é de 3 anos, tendo carga horária total mínima de 2.800 horas, das quais 2.000 horas para execução das atividades científico-acadêmicas, somadas às 400 horas destinadas à Prática como Componente Curricular (PCC) e mais 400 horas estritamente dedicadas à execução do estágio supervisionado (BRASIL, 2002). O estágio, todavia, não deve representar o único momento em que os acadêmicos poderão se aproximar da realidade das salas de aula, justamente por conta de sua duração, sendo essa insuficiente para cumprir papel tão importante na formação docente. Nas palavras de Pimenta e Lima (2005/2006, p. 9), “um curso de formação estará dando conta do aspecto prático da profissão na medida em que possibilite o treinamento em situações experimentais de determinadas habilidades consideradas, a priori, como necessárias ao bom desempenho docente", as quais independem do estágio em que o discente se encontre. 
A despeito da relevância de atividades que, antes mesmo do estágio, levam os discentes das Licenciaturas a se habituarem ao ambiente escolar, destaca-se o valor do Programa Institucional de Bolsas de Iniciação à Docência (Pibid) ${ }^{6}$ e também da PCC, visto que ambos promovem uma aproximação do conteúdo acadêmico com o escolar. De acordo com Anderi (2008), historicamente os cursos de formação docente fazem uma dicotomia entre teoria e prática, o que demonstra "uma visão de conhecimento como algo pronto, acabado, estático e que separava o sujeito que conhece do objeto a ser conhecido" (ANDERI, 2008, p. 73). Tal dissociação decorre da ausência de conhecimento acerca do que de fato é a "prática", somada a uma concepção academicista de pesquisa que a exclui como fator indispensável à teoria. Em muitos casos, a ausência de docentes formadores que não possuem qualificação em Licenciatura, sendo somente bacharéis, somada à falta de vivência na esfera escolar, fortalece a separação entre teoria e prática, negando as atividades de PCC e enfocando a formação de professores num campo estritamente teórico.

A proposta de superação da separação entre teoria e prática ganha destaque com a Lei de Diretrizes e Bases da Educação Nacional 9.394/96, que em seu artigo 61 inciso I designa:

Art.61 - A formação de profissionais da educação, de modo a atender os objetivos dos diferentes níveis e modalidades de ensino e as características de cada fase do desenvolvimento do educando, terá como fundamentos:

I- a associação entre teoria e práticas, inclusive mediante a capacitação em serviço (BRASIL, 1996, p. 26).

Conforme destaca o parecer do Conselho Nacional de Educação (BRASIL, 2002), a prática não se trata de uma imitação da teoria, tampouco uma reflexo da outra. Prática é a forma de realização das coisas, a qual é sempre norteada por uma teoria. De tal modo, a realidade é fundamentada no campo prático e teórico, buscando conceber uma dimensão mais ampla, uma pautada no "fazer algo" e outra na conceituação, respectivamente. Assim, a prática como componente curricular "tem o papel de colocar o futuro professor em contato com as questões ligadas à prática docente e aos problemas da profissão desde o início da formação e nas diferentes disciplinas que compõem o currículo dos cursos de licenciatura" (ANDERI, 2008, p. 77). PCC, portanto, trata-se de uma maneira de demonstrar aos acadêmicos o "saber profissional", sobretudo o saber profissional dos professores, ou aquilo que é trabalhado nas escolas.

Anderi (2008) ao analisar os estudos de Bernard Charlot (2002), afirma que o que designa o "ser professor" é a questão de cotidianamente esse profissional defrontar-se com o inesperado, o que muitas vezes não o faz refletir sobre suas decisões, o que não o

\footnotetext{
6 De acordo com a Portaria no 096, de 18 de julho de 2013, que regulamenta o Programa Institucional de Bolsas de Iniciação à Docência (Pibid), em seu artigo 2o aponta que "o Pibid é um programa da Coordenação de Aperfeiçoamento de Pessoal de Nível Superior (Capes) que tem por finalidade fomentar a iniciação à docência, contribuindo para o aperfeiçoamento da formação de docentes em nível superior e para a melhoria da qualidade da educação básica pública brasileira" (CAPES, 2013, s/p). O documento completa afirmando, no artigo 3o, que "os projetos apoiados no âmbito do Pibid são propostos por Instituições de Ensino Superior (IES) e desenvolvidos por grupos de licenciandos sob supervisão de professores de Educação Básica e orientação de professores das IES" (CAPES, 2013, s/p).
} 
livra de ter de assumir as suas consequências. "A profissão docente é uma prática social, ou seja, como tantas outras, é uma forma de se intervir na realidade social, no caso, por meio da educação que ocorre, não só, mas essencialmente nas instituições de ensino" (PIMENTA; LIMA, 2005/2006, p. 11).

As teorias, de acordo com Pimenta e Lima (2005/2006, p. 12), têm a função de proporcionar "instrumentos e esquemas para análise e investigação, que permitam questionar as práticas institucionalizadas e as ações dos sujeitos e, ao mesmo tempo, de colocar elas próprias em questionamento, uma vez que as teorias são explicações sempre provisórias da realidade". No estágio, a prática insere-se como um elemento institucional, na medida em que nesse período o acadêmico desempenha funções burocratizadas e que lhe fazem somente aproximar-se da realidade. Isto é, existem fatores burocráticos, tanto da escola quanto da própria instituição formadora que direcionam o estagiário em suas ações, visto que a realidade da profissão só será atingida após a formação, já no exercício da docência. A prática institucional, portanto, almeja possibilitar aos futuros professores uma apropriação e um entendimento da complexidade desta, assim como das ações realizadas pelos docentes já atuantes, oportunizando possibilidades de preparação para uma futura atuação profissional.

\section{O QUE MUDA COM O ESTÁGIO SUPERVISIONADO NOS CURSOS DE LICENCIATURA?}

A Graduação, para muitos, revela-se como uma das fases mais especiais e desafiadoras na vida de qualquer pessoa que decide ingressar em um curso superior. Um período constituído por sonhos e realidades, vivências e mutualidades, sabores e dissabores, encontros e desencontros. É, para muitos, se não um teste, uma transição da juventude para a vida adulta; uma experiência marcante e de aprendizados. No Ensino Superior o sujeito tem a chance de se encontrar ou não, seja profissionalmente ou pessoalmente, o que varia de acordo com a escolha de cada um.

Nesse sentido, o estágio é outro demarcador na vida do estudante de Licenciatura, pois é quando o então aluno aproxima-se da realidade de sua profissão, ou seja, é possível ter a dimensão de como será depois de formado, após o término da Graduação, a inserção na área de atuação profissional. Para muitos a confirmação de uma realidade já imaginada e sonhada, em outros casos a conexão com outros horizontes, a descoberta de possibilidades antes não imaginadas. Embora essa "prática" seja contestada, é essa breve experiência durante o estágio que possibilita ao menos tatear ou mesmo situar os formandos do que possivelmente os aguarda no mercado de trabalho. No caso da formação de professores, pode-se afirmar que os alunos

[...] vão para a escola não para praticar, os alunos vão para a escola com o objetivo de compreender e se apropriar da complexidade das práticas institucionais e das ações dos profissionais; os alunos vão para a escola para compreender a escola, para se apropriar da escola. E, nesse sentido, o estágio pode ser entendido como uma instrumentalização, no melhor sentido da noção de instrumentalização teórica (CACETE, 2015, p. 6). 
Aqui então é possível perceber uma mudança da interpretação conceitual do que é o estágio, assim como o que ele acarreta em um curso de formação de professores. Não há aqui a ideia de que os alunos vão para a escola no intuito de ter o contato efetivo com a realidade de sua profissão, afinal, como a própria autora destaca, o estágio deve ser visto como uma "instrumentalização". De tal modo, é um momento da formação que deverá dar conta de fornecer os subsídios para uma atuação profissional futura. Os estagiários vão para as escolas para conhecer e ver como é regido esse ambiente, ou seja, trata-se de uma instrumentalização necessária ao futuro docente. Assim,

[...] o estágio supervisionado não pode ser tomado como uma etapa em que o aluno transpõe os conhecimentos teóricos adquiridos durante a formação inicial formal para a prática. Deve constituir-se como um dos momentos integrantes fundamentais do curso de formação de professores, integrado ao âmbito de todos os componentes curriculares e experiências já internalizadas. Ao mesmo tempo, deve ser tomado como um momento de produção reflexiva de conhecimentos, em que a ação é problematizada e refletida no contexto presente e, após sua realização, momento este que envolve a discussão com a orientação do estágio e pares da área (BELLOCHIO; BEINEKE, 2007, p. 75).

O estágio passará a exigir do aluno os fundamentos apreendidos em sala de aula que foram vistos até então, retomando a premissa do professor também como agente pesquisador, pois durante o estágio o acadêmico deverá manifestar a sua capacidade de investigador, analisando essa etapa da formação como um campo de conhecimento a ser ampliado. A pesquisa deve agora, mais que antes, passar a fazer parte da vida do estagiário como algo indissociável do seu aprendizado como docente em formação, o que não se esgota depois de formado. Não obstante, o diálogo com o(a) professor(a) orientador(a) (tanto da escola, quanto da universidade) deve ser constante nessa etapa de formação, bem como com os colegas que compartilham dessa experiência; isso faz com que conhecimentos sejam compartilhados.

Para Lima (2008), o estágio é um momento que aproxima a escola e a universidade, e vice-versa, cada uma das instituições com seus valores, objetivos, culturas e relações de influência distintas, mas que nesse instante passam a trabalhar em prol de um objetivo comum: a formação docente. Lima (2008) ainda destaca as aprendizagens que decorrem do estágio, apresentando oito lições que podem ser assimiladas pelos estagiários nesse período, as quais se bem aproveitadas serão de grande importância na prática docente. Tais lições podem gerar contribuições para a reflexão no percurso do estágio, podendo influir na constituição da identidade profissional - que já começa a ser composta no estágio e se estende ao longo da carreira - no entendimento do processo educacional que ocorre na escola e na assimilação do magistério. Assim, as oito lições serão destacadas nos parágrafos seguintes, a fim de que se possa compreender o que cada uma orienta.

Em "Lições apreendidas na localização da escola" (LIMA, 2008, p. 201), a autora faz alusão à importância de o estagiário conhecer o lugar em que a escola se encontra, bem como as pessoas e as ações que orientam a dinâmica do espaço em questão; medida que pode contribuir de forma significativa para as aulas ministradas no estágio. $O$ segundo ponto são as "Lições apreendidas na chegada" (LIMA, 2008, p. 201), ou seja, 
o elemento que marca essa lição é o portão de entrada, que pode ser percebido como um fator simbólico no ambiente escolar. Na entrada é possível perceber marcas importantes, não só do meio social que se faz presente naquele lugar, mas da dinâmica empreendida diariamente. $O$ portão nesse caso pode ser associado às cortinas de um palco que ao se abrirem revelam histórias, (multi)culturas, particularidades, os sentimentos e sentidos daqueles que por ali passam, seja para desempenhar seu trabalho diário, estudar, ou somente aqueles que compõem esse fluxo diário, como é o caso de pais ou visitantes (LIMA, 2008).

Há também as "Lições aprendidas entre o dito e o feito, entre o escrito e o vivido" (LIMA, 2008, p. 202), quando o estagiário deve buscar entender como funcionam as políticas da escola, evidentemente que de forma livre, não necessariamente como um professor, mas de modo que consiga assimilar o papel da escola, tanto no âmbito social quanto institucional. É buscar compreender como a escola se comporta em relação às diretrizes e normas que regem o sistema educacional, assim como as que são desenvolvidas em seu interior. As "Lições do Projeto Político Pedagógico da Escola" (LIMA, 2008, p. 202) dizem respeito a conhecer como é o sistema de operacionalização do ambiente escolar, ou seja, a comunidade escolar, seus debates e decisões que influem e se originam diretamente no/pelo coletivo. Além do mais, é a oportunidade de verificar se de fato esse "coletivo" é vigente, se verdadeiramente há a presença dos pais e professores, juntamente com os gestores nas tomadas de decisão, as quais devem ser alicerçadas na realidade vivida do público que compõe essa escola (LIMA, 2008).

As "Lições decorrentes da interação de saberes" (LIMA, 2008, p. 203) trazem a análise das relações entre os agentes que compõem o estágio supervisionado. Trata-se dos professores da universidade, os da escola (Educação Básica) e os estagiários; os (des) encontros de ideias e os possíveis conflitos oriundos; é descobrir e entender o papel de cada um e como esse ocorre. Lima (2008, p. 203) também discorre sobre as "Lições dos procedimentos de investigação" que circunscrevem o caráter de pesquisador que deve ser mantido pelos professores, na intenção de estarem sempre se (re)inventando em relação às suas práticas pedagógicas cotidianas. Do ponto de vista de Libâneo (2006, p. 410), "a aprendizagem da pesquisa implica na promoção de atividades em que o aluno supere suas dificuldades de buscar informações, analisá-las, relacioná-las com os conhecimentos anteriores, dando-lhes significado". Os professores nunca podem perder o seu lado aluno de ser, devem sempre buscar se atualizar, se instrumentalizar de práticas que não os distanciem da realidade de seus alunos, o que constitui um ato de pesquisa e de descobertas ininterruptas (LIMA, 2008).

Lima (2008, p. 203) aborda, para concluir os ensinamentos que podem ser obtidos com a prática do estágio, as "Lições da escola em movimento" e as "Lições da observação e atuação na sala de aula". Esses dois últimos pontos abordados pela autora referem-se ao fato de o estagiário se preocupar com o que sobrevém tanto fora quanto dentro de sala de aula, ou mesmo as ações externas e que também envolvem o interior de uma sala ou durante o decorrer da aula. O estagiário deve buscar entender os procedimentos adotados pela equipe gestora e administrativa da escola, sobretudo em relação aos alunos. "É necessário que o estagiário aprenda a exercitar um olhar pedagógico e atento para entender o que há de estranho nas coisas comuns" (LIMA, 2008, p. 203). 
Uma vez que os olhos do estagiário voltam-se para além daquilo que lhe é apresentado, ele não só sabe direcionar melhor as formas de atuar na sala de aula, mas também com as partes administrativas da escola; é possível afirmar que ele mais aprende do que ensina. No momento em que o aluno/estagiário entende que no ambiente escolar os detalhes fazem a diferença, ele também passa a se ver de forma particular, não mais como um sujeito qualquer dentro daquele espaço, mas como parte integrante, como aquele que por meio de suas ações consegue interferir de modo circunstancial no dia a dia da escola e dos alunos.

Em relação às lições que foram apontadas pode-se inferir que estas contribuem, de forma significativa, com os discentes da Licenciatura. O estagiário deve refletir sobre o "como fazer" dentro da escola. Um dos desafios, quase uma incumbência, atribuídos aos estagiários e futuros professores do século 21 é o de constantemente ter de buscar alternativas/meios que adéquem o ato de ensinar ao de aprender, haja vista que vivemos um momento de profundas mudanças em diversas esferas, o que tem refletido nos estudantes de modo geral. No entendimento de Cacete (2015), os alunos têm demonstrado insatisfação com o modo que os conteúdos, as disciplinas em si, vêm sendo ministrados em sala de aula. O alunado dos dias de hoje é caracterizado pela grande capacidade crítica nas aulas, posto que eles dispõem de uma leva de informações diárias, as quais advêm em boa parte da Internet e dos recursos eletrônicos que Ihes são acessíveis. É preciso, portanto, que o professor se reinvente, busque estimular a imaginação dos alunos e o espírito crítico, de maneira a contribuir para as aulas. Essa cobrança deve-se não só ao fato das mudanças sofridas no ato de ensinar e aprender, mas também em virtude de os professores de hoje em dia serem mais jovens e muitos já terem vivido esses mesmos anseios de seus alunos, o que leva a uma necessidade de repensar o seu fazer pedagógico-didático na prática escolar (LIBÂNEO; PIMENTA, 1999). Cacete, todavia, pondera:

Os alunos não devem sair da escola com conhecimentos que lhes tragam status de geógrafos, historiadores, matemáticos; eles devem encontrar na escola um ambiente de formação cidadã, onde cada disciplina concorre para tal objetivo. É preciso rever os conteúdos e a maneira como estamos trabalhando esses conteúdos na escola. Eles são meios e não fins. São meios para que o aluno compreenda o mundo em sua complexidade (2015, p. 8).

Para tanto, com base na reflexão de Cacete (2015), pressupõe-se que as disciplinas que são ministradas devem permitir aos alunos uma apreensão dos conteúdos, de modo que possam compreender o que está a sua volta e também compreenderem-se dentro de uma estrutura/dinâmica espacial. Fazer com o que o aluno não somente entenda determinada situação, mas que ele possa, a partir de um conhecimento produzido, refletir sobre suas ações, e respectivas consequências, em um contexto do vivido. Trata-se de o aluno se ver não como mais um sujeito, seja no âmbito social ou escolar, mas como aquele que pode fazer a diferença, o que deve começar do seu próprio lugar de vivência; que ele produza frutos, vá além do que lhe é conceitualmente posto (o que a sociedade preestabelece) de forma limitada. É missão do professor procurar ser o referencial e até mesmo o diferencial que os seus alunos buscam e esperam, entretanto cabe destacar que isso não significa ser o "melhor", mas sim dar o seu melhor. 
Desse modo, é no pleno exercício do estágio supervisionado que o aluno/estagiário deve entender a diferença crucial entre "formar-se para ser professor" e "ser professor". Não adianta o licenciando pensar que somente por estudar teorias e diferentes métodos e metodologias ele conseguirá ser o professor que espera, sem antes ele se ver e colocar-se nessa condição. Ser o sujeito (um estagiário ou professor) que busca fazer diferente em sala de aula não significa ser aquele que não se apoia nas teorias, mas sim que possui clareza do que, como, para quem e como diz algo; trata-se de realizar o seu trabalho e ao mesmo tempo de uma maneira diferente, dinâmica. É um desafio grande e, ao mesmo tempo, simples ser o professor que busca fazer o diferencial na vida de seus alunos, nem que seja de maneira descomplicada, mas que essa represente algo a mais no cotidiano desse indivíduo, que agregue ideias, aprendizados. Destarte, o professor em sua infinita criatividade e astúcia em saber lidar com os diferentes conteúdos, precisa também ser humilde o suficiente para poder estar aberto às novas possibilidades, um (re)construir contínuo de sua prática docente, de sua identidade como profissional.

\section{A CONSTRUÇÃO DA IDENTIDADE DOCENTE: UM PERCURSO, VÁRIOS DESAFIOS}

A docência é permeada por diferentes fases. Ao longo dessas fases muitas informações e aprendizados vão sendo adquiridos, o que após reflexões acaba originando uma gama de saberes, os quais são inerentes à atuação docente. A construção de conhecimentos não se dá somente pelo aprendizado institucional, há também os saberes práticos que se originam das experiências, das trocas, independem de teorias propriamente ditas. Esses aprendizados ao longo da carreira vão moldando a atuação do professor, mais que isso, Ihe possibilitam aspectos/características que passam a serem únicas; uma identidade que vai sendo lapidada no decorrer dos anos.

Afinal, no entanto, o que é essa identidade docente? Será mesmo que corresponde a algo já definido? É um processo ou um resultado de determinadas ações? Nóvoa (1992, p. 16) aponta que

a identidade não é um dado adquirido, não é uma propriedade, não é um produto. A identidade é um lugar de lutas e de conflitos, é um espaço de construção de maneiras de ser e de estar na profissão. Por isso, é mais adequado falar em processo identitário, realçando a mescla dinâmica que caracteriza a maneira como cada um se sente e se diz professor.

Assim, na medida em que se entende a identidade não como algo definido, mas como um "processo identitário", pode-se concluir que se trata de uma construção diária, que desponta na formação inicial e se estende ao longo da vida. O aluno torna-se professor no momento em que recebe o título de licenciado e, embora em dada ocasião pause a carreira por circunstâncias distintas, o sujeito nunca deixa de ser professor e de construir sua identidade. Como expõe Souza Neto (2005), o sujeito se torna, continua e morre professor, e nos interstícios dessa sequência apontada, vários são os fatores que condicionam e determinam esses aspectos. A escolha pela função docente, em sua maioria, se dá por conta do interesse, influência ou mesmo sonho que cada um possui em seguir tal profissão. A continuidade é fomentada pelos anseios que cada um tem, 
sejam eles pelo apreço que se desenvolve pela profissão; pela esperança de que um dia ela seja vista com outros olhares, seja valorizada; por acomodação ao que se estabelece ou por esses três aspectos juntos. Sobre o "morrer como professor", isso se dá pela identidade que se cria ao desempenhar a profissão ou então pelo fato de a profissão tornar-se indissociável da pessoa, a ponto de ao lembrar-se dela, as pessoas acabam associando ao ofício desempenhado.

Cavalcanti (2003, p. 195) afirma que "o processo de formação é de fato um processo de autoformação; a formação é um processo contínuo; a formação inicial e continuada tem como princípio a articulação ensino-pesquisa, ação-reflexão". Assim sendo, o professor em sua trajetória como profissional passa por uma formação constante, a qual independe diretamente de critérios institucionais, afinal, em seu cotidiano ele se aperfeiçoa, sobretudo a partir de sua prática e da autoavaliação, as quais o levam a refletir sobre sua atividade profissional. Desse modo, a formação docente adquire caráter atemporal, na medida em que transcende o entendimento reducionista que destaca apenas como o período de formação aquele em que o indivíduo permanece em uma instituição de ensino, seja para capacitação ou aprimoramento.

A identidade se fortalece por meio da ideia de reconhecimento que se forma a partir de "[...] dois polos - o do auto-reconhecimento (como o sujeito se reconhece) e o do alter-reconhecimento (como é reconhecido pelos outros) [...]" (PENNA, 1992 apud GALINDO, 2004, p. 15). Dessa forma, pode-se assegurar que não existe uma identidade sem que o indivíduo se insira como ator principal do processo, que ele assuma uma postura que vá simbolizar, representar, criar e compartilhar os significados de suas ações, do seu "ser profissional", para que assim os outros o percebam como tal.

Ao longo da história, no exercício de sua profissão, o professor, muitas vezes, teve de se defrontar com diferentes desafios ou mesmo limitações, as quais vão desde sua formação às condições de trabalho próprias da profissão. Por conseguinte, em alguns casos negligenciamos a ideia de que o professor precisa se reinventar nos dias atuais, especialmente a partir dos avanços tecnológicos e das mudanças pelas quais a sociedade vem passando em um ritmo muito acelerado. Afinal, este é um profissional marcado pelo fato de ter que superar situações desafiadoras, seja dentro ou fora de sala de aula, lidando com a indisciplina ou tendo de lutar para se firmar perante a sociedade. Um sujeito que para atuar com qualidade necessita desenvolver metodologias que o conduzam para uma composição de um modo de ensinar, de construir os conhecimentos de forma didática, de fazer com que seus alunos compreendam a mensagem passada e que tenham interesse por suas aulas; uma incessante reinvenção de sua prática profissional.

Em sua prática diária o professor deve e tem de buscar ser um profissional que reflita sobre o "ser" e "fazer" na situação de educador, não pode ser conduzido pelos limites tecnicistas que a sociedade lhe impõe, sobretudo pela excessiva quantidade de conteúdos a serem ministrados. É necessário que o profissional engajado cultive a sua sensibilidade, a responsabilidade com o que faz. O professor deve buscar estabelecer um diálogo com as disciplinas que ministra, para que assim possa estabelecer a sua capacidade prática-reflexiva de atuar. 
Cunha, Brito e Cicillini (2006, p. 5, grifo das autoras) ressaltam que "[...] os saberes da experiência fundam-se no trabalho cotidiano e no conhecimento de seu meio. São saberes que brotam da experiência e são por ela validados. Incorpora a vivência individual e coletiva sob a forma de hábitus e de habilidades, de saber fazer e de saber ser". Para isso o docente tem de buscar articular o seu conhecimento à sua experiência, promovendo então uma capacidade de atuação que vise a um ensino-aprendizagem significativo, que estimule a mente de seus alunos, que faça com que o desejo de contribuir na formação desses cidadãos não seja ferido pelos limites de sua profissão. Cavalcanti (2008, p. 87) expõe que

a prática do ensinar é realizada por sujeitos que têm experiências pessoais, emoções, crenças, conhecimentos acadêmicos, conhecimentos cotidianos, que são acionados no processo de trabalho, transformando-se em dispositivos teórico-práticos da ação. Esses dispositivos caracterizam o trabalho docente como profissão e são definidos como parte de uma estrutura institucional e social mais ampla. Portanto, os saberes dos professores em sala de aula não se reduzem a um sistema cognitivo, eles têm componentes sociais, existenciais e pragmáticos.

Sob esse ponto de vista, é possível compreender que o "processo identitário" descrito por Nóvoa (1992, p. 16) somado à fala de Cavalcanti (2008), consiste no ato de concatenar as experiências em suas múltiplas esferas de origem, para que assim originem-se os meios práticos de atuação. Logo, o trabalho do professor passa a ser caracterizado na medida em que esse profissional não parta de recursos ou metodologias que o limitem, mas de meios que ampliem o seu campo de visão e, consequentemente, o de seus alunos. Nesse contexto, concordamos com Souza Neto (2005, p. 258-259) quando argumenta: "[...] aos que optaram por ser e/ou continuar professores por prazer, a vida na profissão é uma celebração diária, pessoal e coletiva, que transforma cada ato, mesmo nos dias mais difíceis, em uma reafirmação da escolha feita em certa altura da existência".

Assim, ser professor e ao mesmo tempo firmar-se como esse profissional nos dias atuais não é uma tarefa fácil, carece de enfrentamentos e firmeza no agir diante dos desafios. Na contemporaneidade, principalmente pela contínua expansão tecnológica, os professores não perdem seus papéis como educadores, esses são assim ressignificados, passam a incorporar novos aspectos, refuncionalizam algumas de suas práticas. Como afirma Toschi (2005, p. 39), "são os professores que devem dirigir o processo de ensino-aprendizagem. São eles que tomam as decisões didáticas na sala de aula, assim, são eles que oferecerão aos seus alunos a formação cultural básica que será o suporte da educação tecnológica". As tecnologias, portanto, são mais uma provocação para que o professor possa vencer e aperfeiçoar a sua prática em sala de aula, mais um meio de promover um raciocínio lógico-didático ante uma ferramenta de trabalho, a qual se manifesta de forma substancial, contínua. Não significa que o professor está ultrapassado, mas sim que não pode, nem deve, tornar-se um sujeito acomodado, ele deve munir-se de ideias e meios que o levem a uma atuação de acordo com seu tempo. 


\section{CONSIDERAÇÕES FINAIS}

Ainda no fervilhar das inquietudes sobre o tema, mas no limitar das palavras, das páginas, o que em momento algum simboliza o concluir das ideias, chegamos à seção final desse trabalho, o que ainda nos instiga a pensar em tantos fatores que são elucidados e que não cabem nesse texto, mas que serão ainda discutidas a posteriori. Afinal, não podemos limitar o que não se limita, o estágio é e deve continuar sendo um objeto de pesquisas para aprimorá-lo a fim de que contribua ainda mais para a formação de professores.

Nesse sentido, o estágio nos cursos de Licenciatura pode ser entendido como um período que nos impulsiona a atravessar uma barreira em que de um lado temos o ideal (teorias) e do outro o concreto (o tatear da prática), fazendo com que o estagiário seja o ponto de intersecção. A tarefa que o estágio traz para os futuros professores leva-os a uma sobrecarga de esforços, tanto físicos quanto emocionais, mas são essas energias que são gastas que, muitas vezes, levam o indivíduo ao refletir sobre o caminho a trilhar na docência. O estágio como um momento de decisão na Licenciatura é algo significativo, pois é a partir daí que podem surgir os professores que servirão como referência para seus alunos, como motivação de fazê-los sempre acreditar, de não desistirem de seus sonhos, mesmo que a realidade vivida seja árdua. É justamente esse fator que se apresenta em déficit na educação hoje em dia, afinal, ter alguém que os inspire e que busque plantar uma semente de esperança, ou mesmo contribuir nesse plantio, é que faz com que os alunos saiam de sua zona de conforto e procurem fazer diferente - é válido lembrar que a diferença não depende do tamanho da decisão, mas do fato de tomar a decisão.

Por fim, não buscamos aqui trazer uma utopia de como ser professor, mas apontar meios que podem ser adotados e que poderão contribuir para que o estagiário, por meio de sua vivência no meio escolar, consiga desenvolver uma concepção de que para ser um professor "diferente" basta começar a fazer ações que levem seus alunos a "saírem da caixinha", refletirem mais sobre o seu meio, suas ações. Um professor, mais ainda, uma escola, que dê asas para o conhecimento e a imaginação de seus alunos pode, a partir disso, ver os ganhos que são gerados com tal atitude; é promover a saída dos casulos, dar asas a quem deve transcender (ALVES, 2012).

Os estudantes da Educação Básica não podem ser depósito de saberes, eles devem ser agentes que contribuam para a construção do conhecimento. Não se trata de ter um professor que fale o tempo todo, que transmita o que sabe initerruptamente em sala de aula, mas um que ouça, que incentive o aluno a falar, pois não há respostas onde não há perguntas, o educador precisa promover a capacidade de seus alunos de querer saber, para que assim ele possa ensinar, mediar. A identidade profissional docente, portanto, passa a ser fundada na medida em que despertamos o interesse dos nossos alunos, o que não é uma tarefa fácil. Desse modo, a atuação do professor se dá de forma efetiva, sendo (re)composta diariamente. 


\section{REFERÊNCIAS}

ALVES, Rubem. A alegria de ensinar. 14. ed. 4. reimp. Campinas: Papirus, 2012.

ANDERI, Eliane Gonçalves Costa. Contribuições da prática curricular e do estágio para a formação do professor. In: ZANATTA, Beatriz Aparecida; SOUZA, Vanilton Camilo de. (org.). Formação de professores: reflexões do atual cenário sobre o ensino da Geografia. Goiânia: Nepeg, 2008. p. 69-83. Disponível em: http:// nepeg.com/livros/formacao-de-professores/. Acesso em: 20 out. 2018.

BARROS, José Deomar de Souza; SILVA, Maria de Fátima Pereira da; VÁSQUEZ, Silvestre Fernández. A prática docente mediada pelo estágio supervisionado. Atos de Pesquisa em Educação, Blumenau, v. 6, n. 2, p. 510-520, maio/ago. 2011. Disponível em: http://gorila.furb.br/ojs/index.php/atosdepesquisa/article/ view/1661/1697. Acesso em: 5 jul. 2018.

BELLOCHIO, Cláudia Ribeiro; BEINEKE, Viviane. A mobilização de conhecimentos práticos no estágio supervisionado: um estudo com estagiários de música da UFSM/RS e da UDESC/SC. Música Hodie: Goiânia, v. 7, n. 2, p. 73-88, jul./dez. 2007. Disponível em: https://www.revistas.ufg.br/musica/article/view/3303. Acesso em: 15 jul. 2018.

BRANDÃO, Carlos Rodrigues. Nós, os humanos: do mundo à vida, da vida à cultura. São Paulo: Cortez, 2015.

BRASIL. Congresso. Senado. Lei no 9394 de 20 de dezembro de 1996. Estabelece as Diretrizes e Bases da Educação Nacional. Brasília, 2005. Disponível em: https://www2.senado.leg.br/bdsf/bitstream/handle/ id/70320/65.pdf. Acesso em: 5 jul. 2018.

BRASIL. Parecer CNE no 28 de 2 de outubro de 2001. Estabelece a duração e a carga horária dos cursos de formação de professores da Educação Básica, em nível superior, curso de licenciatura, de graduação plena. Diário Oficial da União, Poder Executivo, Brasília, 18 jan. 2002. Disponível em: http://portal.mec. gov.br/cne/arquivos/pdf/028.pdf. Acesso em: 5 jul. 2018.

CACETE, Núria Hanglei. Formação do professor de Geografia: sobre práticas de ensino e estágio supervisionado. Revista Casa da Geografia de Sobral, Sobral, v. 17, n. 2, p. 3-11, jul./dez. 2015. Disponível em: https://dialnet.unirioja.es/servlet/articulo?codigo=5156907. Acesso em: 5 jul. 2018.

CAPES. Portaria no 096, de 18 de julho de 2013. Dispõe sobre o regulamento do Programa Institucional de Bolsas de Iniciação à Docência (Pibid). Brasília: Capes, Disponível em: https://www.capes.gov.br/images/stories/download/legislacao/Portaria_096_18jul13_AprovaRegulamentoPIBID.pdf. Acesso em: 2 set. 2019.

CAVALCANTI, Lana de Souza. A formação do professor de Geografia - o lugar da prática de ensino. In: TIBALLI, Elianda Arantes; CHAVES, Sandramara Matias (org.). Concepções e prática em formação de professores: diferentes olhares. Rio de Janeiro: DP\&A, 2003. p. 189-206.

CAVALCANTI, Lana de Souza. Formação inicial e continuada em Geografia: trabalho pedagógico, metodologias e (re)construção do conhecimento. In: ZANATTA, Beatriz Aparecida; SOUZA, Vanilton Camilo de. (org.). Formação de professores: reflexões do atual cenário sobre o ensino da Geografia. Goiânia: Nepeg, 2008. p. 85-102. Disponível em: http://nepeg.com/livros/formacao-de-professores/. Acesso em: 20 out. 2018.

CAVALCANTI, Lana de Souza. Geografia escolar e a cidade: ensaios sobre o ensino de Geografia para a vida urbana cotidiana. 3. ed. Campinas: Papirus, 2010.

CUNHA, Ana Maria de Oliveira; BRITO, Taita Talamira Rodrigues; CICILLINI, Graça Aparecida. Dormi aluno(a)... acordei professor(a): interfaces da formação para o exercício do Ensino Superior. In: REUNIÃO ANUAL DA ANPED - ASSOCIAÇÃO NACIONAL DE PÓS-GRADUAÇÃO E PESQUISA EM EDUCAÇÃO, 29., 2006, Caxambu. Anais [...], Caxambu, 2006. p. 1-15. Disponível em: http://29reuniao.anped.org.br/trabalhos/ trabalho/GT11-2544--Int.pdf. Acesso em: 22 out. 2018.

CURY, Augusto. Pais brilhantes, professores fascinantes: a educação inteligente; formando jovens educadores e felizes. Rio de Janeiro: Editora Sextante, 2003.

GALINDO, Wedna Cristina Marinho. A construção da identidade profissional docente. Psicologia: Ciência e Profissão, Brasília, v. 24, n. 2, p. 14-23, jun. 2004. Disponível em: http://pepsic.bvsalud.org/scielo.php?pi$\mathrm{d}=\mathrm{S} 1414-98932004000200003 \&$ script=sci_abstract\&tlng=es. Acesso em: 20 out. 2018.

LIBÂNEO, José Carlos. Organização e a gestão da escola: teoria e prática. 3. ed. Goiânia: Alternativa, 2006. LIBÂNEO, José Carlos; PIMENTA, Selma Garrido. Formação de profissionais da educação: visão crítica e perspectiva de mudança. Educação e Sociedade, Campinas, v. 20, n. 68, p. 239-277, jul./set. 1999. Disponível em: http://www.scielo.br/pdf/es/v20n68/a13v2068.pdf. Acesso em: 20 jun. 2018. 
LIMA, Maria Socorro Lucena. Reflexões sobre o estágio/prática de ensino na formação de professores. Revista Diálogo Educacional, Curitiba, v. 8, n. 23, p. 195-205, jan./abr., 2008. Disponível em: https://periodicos.pucpr.br/index.php/dialogoeducacional/article/view/4015. Acesso em: 20. out. 2018.

NÓVOA, Antonio. Formação de professores e profissão docente. Lisboa: Dom Quixote, 1992.

PELOZO, Rita de Cássia Borguetti. Prática de ensino e o estágio supervisionado enquanto mediação entre ensino, pesquisa e extensão. Revista Científica Eletrônica de Pedagogia, Garça, ano V, n. 10, s/p, jul./ dez. 2007. Disponível em: http://faef.revista.inf.br/imagens_arquivos/arquivos_destaque/J3yAMQWorvNVHM6_2013-6-28-15-23-42.pdf. Acesso em: 5 jul. 2018.

PIMENTA, Selma Garrido. O estágio na formação de professores: unidade, teoria e prática. 2. ed. São Paulo: Cortez, 1994.

PIMENTA, Selma Garrido; LIMA, Maria Socorro Lucena. Estágio e docência: diferentes concepções. Revista Poiesis, Catalão, v. 3, n. 3-4, p. 5-24, edição especial, 2005/2006. Disponível em: https://www.revistas. ufg.br/poiesis/article/view/10542/7012. Acesso em: 8 jul. 2018.

PONTUSCHKA, Nídia Nacib. A diversidade da formação do professor: discurso e práxis. In: ENDIPE - ENCONTRO NACIONAL DE DIDÁTICA E PRÁTICAS DE ENSINO, 16., 2012, Campinas. Anais [...]. Campinas: Unicamp (Universidade de Campinas), p. 000094-000106, 2012. Disponível em: http://docplayer.com.br/ 80848361-A-diversidade-da-formacao-do-professor-discurso-e-praxis.html. Acesso em: 10 jul. 2018.

RODRIGUES, Micaías Andrade. Quatro diferentes visões sobre o estágio supervisionado. Revista Brasileira de Educação, Rio de Janeiro, v. 18, n. 55, p. 1.009-1.034, out./dez. 2013. Disponível em: http://www.scielo.br/pdf/rbedu/v18n55/11.pdf. Acesso em: 5 jul. 2018.

SCALABRIN, Izabel Cristina; MOLINARI, Adriana Maria Corder. A importância da prática do estágio supervisionado nas licenciaturas. Unar, Araras, v. 7, n. 1, jan./jun. 2013. Disponível em: http://revistaunar. com.br/cientifica/documentos/vol7_n1_2013/3_a_importancia_da_pratica_estagio.pdf. Acesso em: 5 jul. 2018.

SOUZA NETO, Manoel Fernandes de. O ofício, a oficina e a profissão: reflexões sobre o lugar social do professor. Cad. Cedes, Campinas, v. 25, n. 66, p. 249-259, maio/ago. 2005. Disponível em: http://www.scielo. br/pdf/ccedes/v25n66/a07v2566.pdf. Acesso em: 7 jul. 2018.

TOSCHI, Mirza Seabra. Tecnologia e educação: contribuições para o ensino. Série-Estudos, Campo Grande, n. 19, p. 35-42, jan./jun. 2005. Disponível em: http://www.gpec.ucdb.br/serie-estudos/index.php/serie-estudos/article/view/443. Acesso em: 8 jun. 2018. 